\title{
RISK OF SOCIOECONOMIC, NUTRITIONAL, AND PSYCHOLOGICAL WELL BEING ON TUBERCULOSIS AND DIABETES COINCIDENT IN SURABAYA
}

M.A. Isfandiari ${ }^{1}$, C.U. Wahyuni ${ }^{1}$, A. Pranoto ${ }^{2}$.

1.Faculty of Public Health Universitas Airlangga Surabaya, Epidemiology, Surabaya, Indonesia.

2.Surabaya Diabetes and Nutrition Center Faculty of Medicine Universitas Alrlangga-dr. Soetomo Hospital, Internal Medicine, Surabaya, Indonesia.

\section{Background}

Type 2 Diabetes Mellitus patients are susceptible to many infections due to abnormalities of the immune system that occurs as the impact of chronic hyperglycemia, and one the most common infection is pulmonary tuberculosis. Based on medical records of dr. Soewandi Public Hospital in Surabaya during 2016, in line with data from Surabaya City Health Office, the number of TB-DM co-incident patients mostly came from Tambaksari Sub-district, an slum area lied at East Surabaya.

\section{Aim}

This study was conducted to analyze socioeconomic factors, nutritional status, and psychological wellbeing as the risk factors of pulmonary tuberculosis and type 2 diabetes mellitus coincidence.

\section{Method}

The design of this study is case control with the age and gender were matched between both group, involving 76 type 2 Diabetes Mellitus patients from 3 Health centers and one pulmonary Hospital in Surabaya consisting of 38 patients with pulmonary tuberculosis coincident with type 2 Diabetes Mellitus as case group and 38 patients with only type 2 diabetes without pulmonary tuberculosis as control during November 2016 until April 2017. We analyze the relationship between TB DM co-incident and socioeconomic factor, nutritional status, and psychological well being. Socioeconomic data was collected using questionnaire, nutritional status was collected by anthropometric measurement and psychological well being was measured using WHO 5-well being index (WHO-5). Data was analyzed using logistic regression.

\section{Results}

The result showed that among socioeconomic factor, Work status was significant risk factor $(\mathrm{p}$-value $=0.022)$ with Odds Ratio (OR) 3.297 and family income (classified based on minimum income rate in Surabaya) also significant risk factor ( $p$-value $=0.009)$ of tuberculosis and diabetes coincidence with OR 13.214. Nutritional status and psychological well being were also significant risk factors of tuberculosis and diabetes coincidence as well, with p-value 0.001 (OR 17.889) and $0.001(\mathrm{OR}=5.750)$, respectively.

\section{Discussion}

It might be concluded that patient of type $2 \mathrm{DM}$ who did not work was at risk 3.297 fold to suffer from pulmonary tuberculosis, compared to those who work. Type 2 diabetes mellitus patients who earn less than Surabaya minimum income

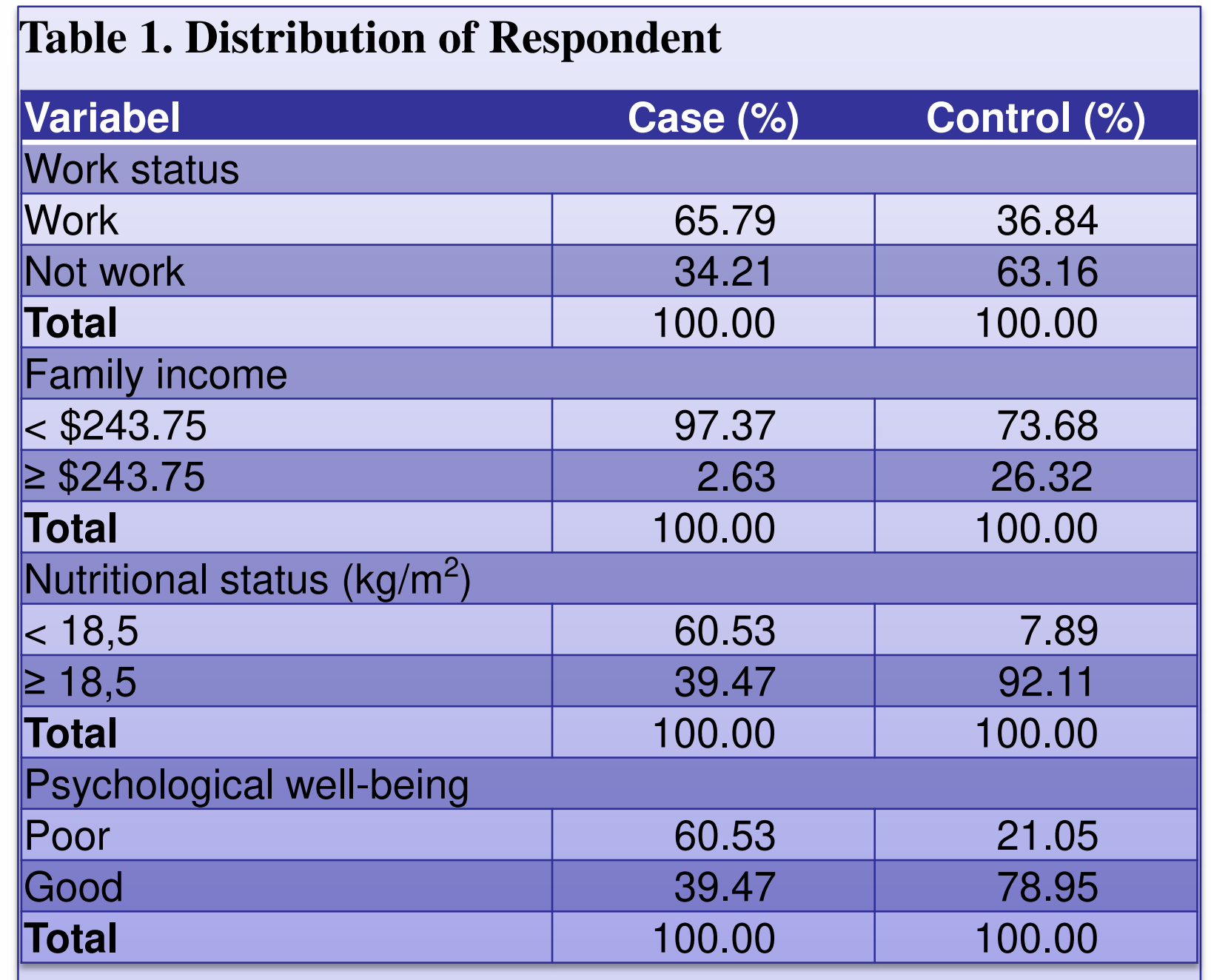

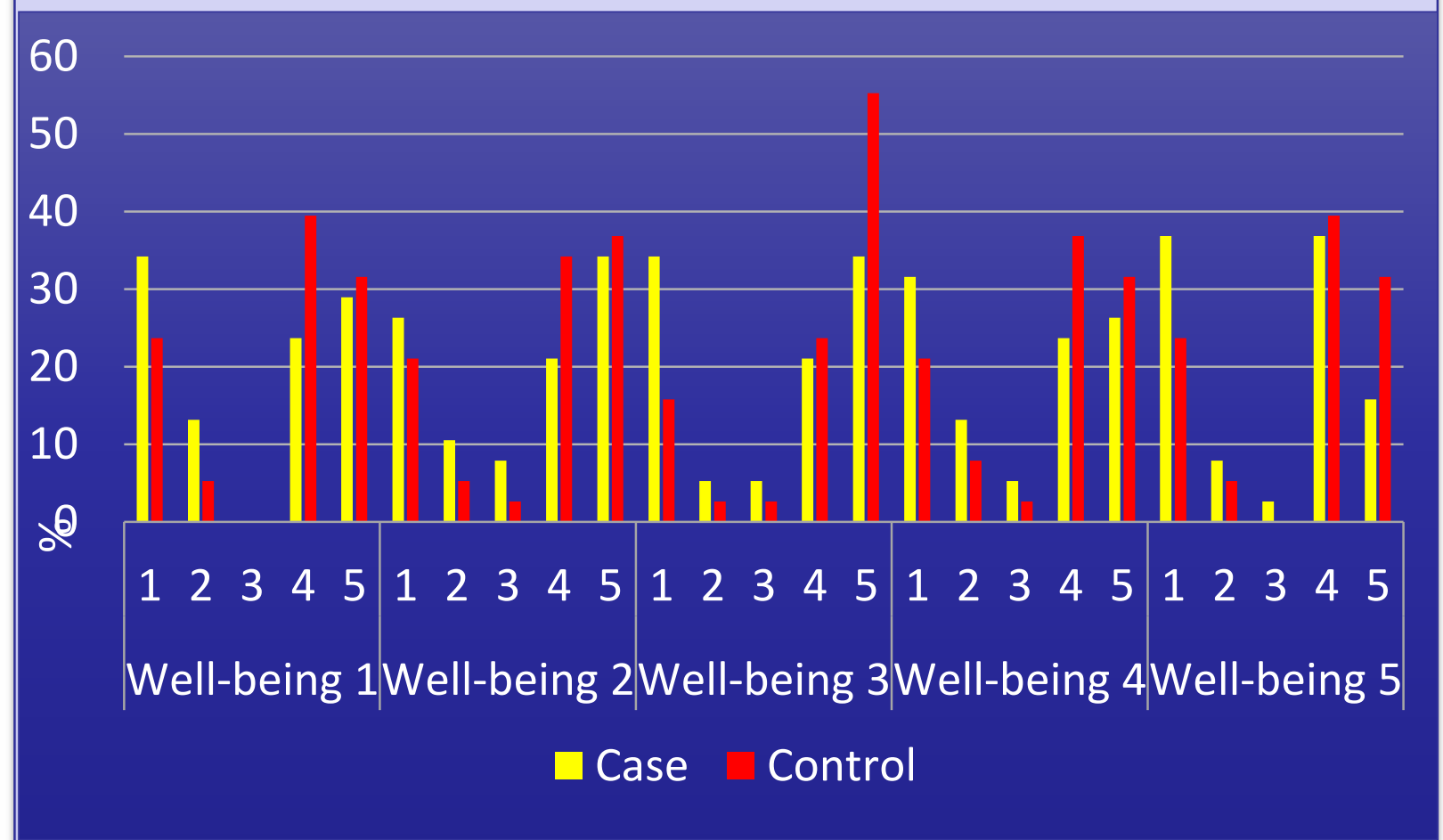

Picture 1. Graphic of Psychological Well-Being

rate have risk 13,214 fold to suffer from pulmonary tuberculosis compared to patient type 2 Diabetes mellitus who earn more than minimum income rate. Type 2 diabetes mellitus patients with BMI $<18.5$ had a risk of 17,889 fold to suffer pulmonary TB compared with diabetes patients with normal nutritional status (IMT $18,5-25.0$ ). Type 2 diabetes mellitus with poor psychological well being has a risk of 5.75 fold to suffer from pulmonary TB than patients with good mood.

Thus, it is suggested that the quality of health service and diabetes treatment in health service and pulmonary hospital in Surabaya for type 2 diabetes mellitus patient with low socioeconomic and nutritional status should be prioritized, as well as keeping the patients in a well state of mood in order to avoid tuberculosis coincidence among these diabetes mellitus patients. 